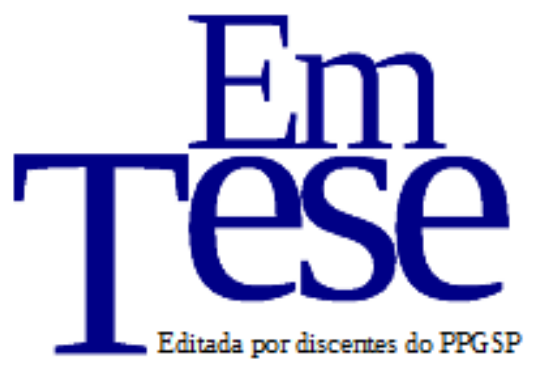

UFSC

PPG SP PROG RAMA DE

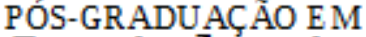

Sociologia

Política

v. 14, n. 1, jan./jun., 2017

\title{
Revendo mapeamentos do pensamento brasileiro ${ }^{1}$
}

Marco Antonio Perruso ${ }^{2}$

Resumo: Este artigo trata de alguns mapeamentos do pensamento político e social brasileiro, tema e esforço classificatório ainda rarefeito nas ciências sociais nacionais. A partir desta revisão e do registro de passagens de obras do nosso pensamento, formula-se uma hipótese de mapeamento do pensamento brasileiro, referido aos principais lugares sociais de ancoragem da produção intelectual nacional: o mercado (lugar do exercício do espírito do capitalismo); o Estado-Nação (lugar do exercício do poder político-burocrático, modalidade de ação instrumental diferente da anterior); a universidade (e outras instituições assemelhadas), domínio do capital cultural/intelectual, distinto dos capitais econômico e político; e as classes e movimentos sociais de extração popular, que remetem à participação política dos setores subalternizados de nossa sociedade.

Palavras-chave: pensamento político e social brasileiro. Intelectuais. Classes populares.

\begin{abstract}
This article exposes some mappings of Brazilian political and social thought, theme and classificatory effort still rarefied in the national social sciences. Based on this review and the demarcation of passages of works of our thought, a hypothesis is formulated to map Brazilian thought, referring to the main social places of anchorage of national intellectual production: the market (place of the exercise of the spirit of capitalism); the Nation-State (place of the exercise of political-bureaucratic power, modality of instrumental action different from the previous one); the university (and other similar institutions), the domain of cultural/intellectual capital, distinct from economic and political capital; and social classes and movements of popular extraction, which in turn refer to the political participation of the subalternized sectors of our society.
\end{abstract}

Key-words:Brazilian political and social thought, intellectuals, popular classes

\footnotetext{
${ }^{1} \mathrm{O}$ presente artigo expõe os primeiros resultados de minha pesquisa de pós-doutorado "A esquerda fora do lugar no séc. XXI: o pensamento brasileiro e seus lugares sociais", realizada na Usp sob supervisão de Bernardo Ricupero, do Departamento de Ciência Política.

${ }^{2}$ Universidade Federal Rural do Rio de Janeiro, Professor Adjunto de Sociologia, Pós-Doutorando em Ciência Política - USP.
} 
O presente artigo esboça um mapeamento do pensamento brasileiro que se concentra em delimitar com rigor os principais lugares sociais, dotados de larga continuidade histórica, que têm fomentado a produção intelectual sobre o país. Tal esboço, resultado de pesquisa em fase inicial de desenvolvimento, baseia-se na revisão de alguns mapeamentos consagrados do pensamento político e social nacional (outros ainda serão revistos oportunamente) e em algumas obras exemplares na interpretação do Brasil. Os mapeamentos do nosso pensamento não são numerosos. Além disso, parece inexistir uma taxonomia a respeito do pensamento brasileiro que observe os espaços sociais, institucionais ou de classe por meio dos quais historicamente os intelectuais nacionais explicam o país, buscando conservá-lo como sempre foi ou, na maioria das vezes, mudá-lo em sentido modernizante. Tais lugares sociais, que recorrentemente inspiram ou sediam reflexões políticas e sociais dedicadas a realidade nacional, seriam o mercado, o Estado-Nação, a universidade (e outras instituições assemelhadas) e, por fim, as classes e movimentos sociais de extração popular.

O mapeamento ora proposto, ainda preliminarmente, parte primeiramente, da revisão de certos mapeamentos anteriores - de Lamounier (1977), Sadek (1982), Brandão (2005) e Vianna (1991). Em segundo lugar, de determinadas obras clássicas de nosso pensamento político e social, revisitadas panoramicamente em função de algumas passagens representativas ou especialmente sugestivas - as quais forneceriam evidências promissoras para o mapeamento ora formulado.

\section{Alguns mapeamentos do pensamento político e social brasileiro}

Ao se retomar alguns mapeamentos - ou classificações - fundamentais relativos ao pensamento político e social brasileiro, algumas similaridades e convergências podem ser destacadas.

Bolívar Lamounier, fazendo referência aos intelectuais antiliberais do início do séc. XX como objeto de estudo, indica quatro modos de ler o pensamento político e social: o institucionalcientificista, o historicista-nacionalista, o classista e o autoritarismo esclarecido (LAMOUNIER, 1977, p.349-357). Já Maria Tereza Sadek (1982), ao compilar a bibliografia existente até fins dos anos 1970 a respeito do pensamento brasileiro, registra quatro paradigmas analíticos: o da institucionalização da atividade científica, o nacionalista, o classista e o conciliatório - quase os mesmos do mapeamento elaborado por Lamounier. Em ambos os mapeamentos se conjugam maneiras típicas de operar a análise do pensamento brasileiro e intelectuais representativos correspondentes.

O enfoque institucional-cientificista (ou da institucionalização da atividade científica) cujos representantes destacados seriam Florestan Fernandes e Fernando Azevedo - postula que o 
método de elaboração do pensamento, e não o conteúdo elaborado, é a medida maior da avaliação da consistência ou adequação do pensamento político e social brasileiro. Tal enfoque possui como ideia-força central a ciência ou a razão em sua modalidade universitária/acadêmica de efetivação no mundo social, que quase sempre é acompanhada do ideal da neutralidade científica, classicamente formulada em chave weberiana.

Ao contrário, a perspectiva historicista-nacionalista (em Lamounier) ou simplesmente nacionalista (em Sadek) referencia a qualidade ou pertinência do pensamento brasileiro não à dimensão procedimental da ciência (o método científico, propriamente), como o enfoque anterior, mas justamente ao conteúdo produzido, a partir de um balizamento específico: a Nação (ou o Estado-Nação). Isto é, o pensamento é mensurado por sua correspondência com o que supõe-se ser a realidade da sociedade nacional brasileira em seu desenvolvimento histórico. Obviamente, se tal perspectiva analítica é, com o perdão do termo, conteudista, há a valorização e seleção de certos conteúdos do pensamento - questões, pautas, demandas, proposições - vistos como apropriados à modernização da sociedade brasileira (no sentido genérico de superação da sociedade tradicional). Em consonância com este enfoque, o Estado costuma ser tomado como o instrumento por excelência capaz de levar nossa sociedade ao objetivo modernizante, bem como se erige uma intelligentsia vinculada ao Estado como ator estratégico para a condução deste processo, que seria capaz de dar conta dos interesses gerais da Nação, os quais não se confundiriam com os interesses de classes e demais grupos sociais.

É importante notar que o viés cientificista, comumente mais percebido no caso do primeiro enfoque analítico do pensamento brasileiro (tanto que está presente nas duas versões de sua designação), também pode ser denunciado na perspectiva historicista-nacionalista. Seja pela ênfase na apuração dos conteúdos reais, "corretos", do pensamento - com a aferição orientada pela trajetória da sociedade nacional - seja pela crença em uma camada intelectual paraestatal capaz de propor, com legitimidade (não só política, mas científica), diagnósticos e soluções para nossos problemas. Aqui não haveria uma ciência neutra, como no primeiro enfoque, mas uma razão engajada - especificamente num Estado modernizador capaz de levar a Nação adiante.

Segundo esses dois mapeamentos, representantes da perspectiva nacionalista seriam Guerreiro Ramos e, apenas no mapeamento de Sadek, Wanderley Guilherme dos Santos. Isto porque Lamounier destaca o viés analítico formulado por Santos como um enfoque próprio, o autoritarismo esclarecido. Seguindo o mapeamento de Sadek, creio que ele pode ser visto como a versão mais sofisticada dentre as que compõem o paradigma nacionalista. $O$ autoritarismo esclarecido pontua uma ordem liberal burguesa como referente maior de meta sócio-políticacultural a ser alcançada pela sociedade brasileira, por meio de um protagonismo estatal propiciado por elites políticas/burocráticas (certamente uma intelligentsia) capazes de vocalizar os interesses 
nacionais.

Talvez não por acaso, essa suposição de que existam interesses nacionais comuns a todas as classes e grupos sociais constitutivos de uma sociedade demarcada pelas fronteiras do EstadoNação, crença que subjaz a todas as versões do paradigma nacionalista, está presente com centralidade no paradigma conciliatório proposto por Sadek (que inexiste no mapeamento de Lamounier). Nele há o viés analítico que visualiza as diferenças e os conflitos no pensamento e na sociedade nacional como ajustáveis por meio de uma política harmonizadora típica do Brasil. Tal paradigma pode ser relacionado às vertentes conservadoras ou tradicionalistas de nosso pensamento.

Por fim, o paradigma classista, igualmente nomeado por Lamounier e Sadek, pressupõe uma relação de determinação ou condicionamento entre classe social e pensamento, típica do marxismo (nos pares infraestrutura-superestrutura ou ser-consciência). Um representante destacado de tal enfoque é Roberto Schwarz. Recorrente, tal perspectiva analítica por vezes é acionada de modo dogmático ou rudimentar. Segundo tal viés, e comparando-o com os anteriores, o impulso social do pensamento, digamos assim, advém não dos lugares sociais singulares onde se produz ciência e se exercita a razão (conforme proposto no enfoque institucional-cientificista), nem do espaço social mais largo da Nação ou do Estado-Nação (como propugnado pelos enfoques nacionalista, conciliatório e do autoritarismo esclarecido - todos aparentados, a meu ver), mas das classes sociais onde estão circunscritos os diversos agrupamentos intelectuais. É mister ressaltar aqui a presença de outra acepção a respeito da intelectualidade, na qual os intelectuais são menos capazes de se destacar ou se desconectar dos demais grupos sociais do que a chamada intelligentsia.

Sintomaticamente, quando se classificam as correntes de pensamento - e não os modos de analisá-las - presentes na sociedade brasileira em sua trajetória histórica, é possível estabelecer aproximações entre o pensamento em si e as maneiras de percebê-lo, malgrado a diferença de objeto de estudo.

Ao observarmos as linhagens do pensamento político brasileiro traçadas por Gildo Marçal Brandão (2005, p.236-249), tais aproximações são curiosas. Sua atualização do conceitual relativo ao idealismo orgânico, formulado originalmente por Oliveira Vianna, nos remete à força do Estado e do nacionalismo na trajetória da sociedade brasileira, elementos que também são estratégicos na perspectiva analítica nacionalista do pensamento político e social brasileiro. É mais difícil estabelecer relação entre a linhagem idealista constitucional de nosso pensamento e o enfoque institucional-cientificista. Ainda sim é possível, se pensarmos no universalismo ocidentalizante de nossos liberais, que possui conexões com a centralidade da ciência e da universidade no avanço dito progressista da modernização do Ocidente, subjacente àquele enfoque. 
Já sobre o pensamento radical de classe média e o marxismo de matriz comunista (as primeiras concepções antiaristocráticas do país), as outras duas linhagens do pensamento político brasileiro desenhadas por Brandão (2005, p.236), é visível que possuem uma notável marca do corte classista em suas configurações enquanto pensamento. O primeiro possui a clivagem social de classe na própria designação, enquanto o segundo está referido diretamente às classes trabalhadoras brasileiras. Desnecessário se alongar a respeito da afinidade dessas linhagens de pensamento - caracterizadas, entre outros elementos, por sua rebeldia diante do status quo - com um olhar social que percebe com contundência as desigualdades de classe, absurdamente notórias na história brasileira, inclusive suas consequências para o plano das ideias.

Além disso, Brandão (2005, p.239) correlaciona as análises de Guerreiro Ramos e Wanderley Guilherme dos Santos com a linhagem idealista orgânica iniciada por Visconde de Uruguai e continuada por Oliveira Vianna. Isto é, as reflexões dos dois primeiros autores, no que tange ao mapeamento do pensamento político e social brasileiro, dão prosseguimento à trajetória deste mesmo pensamento - com seus respectivos vieses analíticos. Assim, Brandão (2005, p.239) procede igualmente em relação ao mapeamento proposto por Lamounier, que é lido então como continuidade da linhagem do idealismo constitucional iniciada por Tavares Bastos.

Por conseguinte, Brandão chama atenção para uma certa dimensão de continuidade do pensamento político e social brasileiro produzido por líderes políticos das classes dominantes do Brasil Império, com o elaborado por ensaístas dos primórdios do século XX e, ainda, com o pensamento político e social exercitado profissionalmente nas universidades por acadêmicos na área de estudos do mesmo nome. Ou seja, os trabalhos de Guerreiro Ramos, Wanderley Guilherme dos Santos e Bolivar Lamounier são "tanto marcos desse interesse acadêmico pela história intelectual brasileira como momentos eles próprios de reconstrução das origens ideais de correntes ideológicas socialmente enraizadas" (BRANDÃO, 2005, p.239).

O mesmo autor assevera com propriedade: "uma das particularidades do estudo do pensamento político é que ele aspira a ser parte constitutiva do objeto estudado" (BRANDÃO, 2005, p.238). A partir dessa constatação, é possível acrescentar o seguinte: não apenas cada profissional acadêmico faz pensamento político e social ao pesquisar pensamento político e social; além disso, cada mapeamento dos modos de pensar o pensamento político e social não deixa de ser um olhar, perspectivado pela tradição da qual é tributário o intelectual acadêmico proponente da mesma, a respeito das obras do pensamento em geral, mas talvez principalmente um olhar crítico que tem como alvo as outras tradições de pensamento, inclusive os outros mapeamentos de pensamento - os outros olhares, as outras perspectivas analíticas - a eles referidas.

Voltando aos mapeamentos das correntes do pensamento brasileiro, antes de Brandão, Luiz Werneck Vianna (1991) elencou tais correntes no escopo mais amplo da América Latina. Ele 
destaca os americanistas - liberais, correspondentes ao idealismo constitucional - e os iberistas nacionalistas defensores da proeminência estatal na sociedade, correspondentes ao idealismo orgânico.

Para Vianna, os americanistas/liberais sempre propugnaram pela ocidentalização das sociedades brasileira e latino-americanas - o que condiz com o universalismo anteriormente salientado, a propósito do mapeamento de Brandão. Em contraposição a tal universalismo, os iberistas sempre ressaltaram as singularidades das sociedades nacionais - no caso, do Brasil e da América Latina. Exclusivamente por meio do Estado, o nacionalismo poderia tirar partido da sua vantagem do atraso diante da exportação da moderna experiência europeia e estadunidense como modelo societário (VIANNA, 1991, p.147-148). De novo aqui teríamos uma aproximação entre mapeamento do pensamento em si e mapeamento dos modos de ver os pensamentos.

Porém, Vianna chama atenção para as contradições de nossos liberais, que não conseguiam ou não queriam repetir a performance social dos seus companheiros de autodesignação ideológica na Europa e nos Estados Unidos: não admitiam o fim do exclusivo agrário nem da escravidão e temiam perder "o controle social das massas do campo" garantido justamente pela força do Estado ocupado e dirigido pelos iberistas, hegemônicos nos próprios estratos sociais dominantes. Assim, como o americanismo liberal padecia das características não-liberais das sociedades latinoamericanas, acabavam reféns ou adeptos do Estado (VIANNA, 1991, p.154; também p.168-169).

Mas se estamos neste momento debruçados sobre os liberais brasileiros, com estes revolvendo-se em meio ao histórico protagonismo estatal nacional, como pensar a respeito do ente (que seus predecessores europeus elegeram como) central da teoria liberal - o mercado - na trajetória brasileira? Não à toa, Lamounier, na obra antes citada (1977), coloca o mercado frente a frente ao Estado, como ideias-força opostas presentes no pensamento brasileiro.

No entanto, não emerge em seu mapeamento, pelo menos não diretamente, a referência do mercado para se pensar o pensamento político e social brasileiro - ao contrário da Nação/Estado, da ciência/razão e das classes sociais. Já nos mapeamentos das correntes do pensamento brasileiro, o liberalismo - como objeto - aparece enquanto americanismo (Vianna) ou idealismo constitucional (Brandão). Da mesma maneira, o nacionalismo (iberismo e idealismo orgânico, respectivamente) e o classismo (das classes média ou trabalhadora) fazem-se presentes.

Será que o liberalismo do Brasil não apenas teve crônica dificuldade de "encontrar sustentação social e política", se restringindo "a uma ideologia dos homens de negócio e de liberais doutrinários" (VIANNA, 1991, p.181), como também intelectualmente não foi capaz de propor, de alguma maneira, no nível analítico que fosse possível, o mercado como eixo perspectivador de um modo próprio de leitura sobre o pensamento político e social brasileiro, isto é, o mercado como impulsionador de nosso pensamento? Ou estaria o liberalismo contemplado de 
certa forma numa das outras perspectivas analíticas em tela?

Indo mais longe, pode-se colocar uma indagação ainda mais relevante, a meu ver: em se tratando do enfoque analítico classista sobre o pensamento brasileiro, efetivamente quais fundamentações de classe tem sido consideradas relevantes para impulsionar socialmente uma reflexão política e social? É necessário, creio, verificar quais classes e grupos sociais são observados não apenas como objeto do pensamento, mas como inspiradores das ideias políticas e sociais e da cultura brasileira.

\section{Considerações com vistas a outro mapeamento do pensamento brasileiro}

Busca-se aqui esboçar, em caráter preliminar, um mapeamento do pensamento brasileiro que, embora partindo dos anteriores, concentre-se nos lugares sociais de produção e de inspiração das reflexões sócio-políticas a respeito do Brasil. Proponho que os principais lugares ou espaços sociais, capazes de estimular ou acolher o pensamento político e social brasileiro, seriam os seguintes: o mercado; o Estado-Nação; a universidade (e outras instituições assemelhadas); e as classes e movimentos sociais de extração popular.

O mercado é aqui entendido como o espaço social onde se exercita privilegiadamente o espírito do capitalismo na acepção weberiana (HABERMAS, 1987). Tal fenômeno é divisor de águas na fundação e constante reprodução e intensificação da modernidade necessariamente capitalista. Além disso, o mercado impulsionou - e continua a impulsionar incessantemente - a elaboração da primeira tentativa de explicação da sociedade moderna, o liberalismo burguês, com seus pressupostos individualista e utilitarista. Embora enquanto houvesse escravidão no Brasil a existência deste ente chamado mercado fosse questionável, a importação das ideias liberais europeias e estadunidenses para nossa sociedade quase sempre ocorreu - o que foi gerando, inclusive o incômodo de nossas ideias serem percebidas intuitivamente como "fora do lugar" ou numa mirada dualista (SCHWARZ, 2001, p.59-61).

O Estado-Nação, por sua vez, é entendido como o espaço social que, sendo composto por estruturas institucionais estatais, funciona tendo em vista o exercício de um poder político, bem como mediante uma organização que ou é burocrática ou tende a emular a burocracia. Como tal, também configura, junto com o mercado, as sociedades modernas e contemporâneas (HABERMAS, 1987). Mercado e Estado são lugares por excelência da vigência de ações do tipo instrumental. As ideias políticas e sociais normalmente associadas a agentes estatais (ou a agentes inspirados pela esfera estatal) são o nacionalismo, o positivismo, o funcionalismo, os diversos conservadorismos e tradicionalismos, bem como variados reformismos e populismos. Da mesma maneira que visto com o mercado, pode-se problematizar desde quando o Brasil passou a ter um 
Estado em sua feição moderna, mas, também analogamente, os Estados-Nação europeus e estadunidense foram tomados como exemplos por nós.

As universidades e outras instituições correlatas, mais propriamente o campo acadêmico como se pode nomear recorrendo a Bourdieu, são compreendidas como o espaço social consagrado, na contemporaneidade, à produção do conhecimento legitimado socialmente enquanto ciência. E onde, além disso, seus membros, professores/pesquisadores, possuem significativa, ainda que variável, autonomia diante de outros poderes sociais, como o econômico (advindo do mercado) e o político (referido ao Estado-Nação). Por isso também, mas não só, a produção intelectual acadêmica é caracterizada por grande pluralidade teórica e ideológica. $\mathrm{Na}$ trajetória brasileira, desde os anos 1930 nossas universidades foram se consolidando.

Por fim, quando se traz à baila, para efeito de um mapeamento relativo ao pensamento político e social brasileiro, as classes e movimentos sociais de extração popular, o faço primeiramente com o intuito de ressaltar a pequena visibilidade de nossos setores sociais historicamente subalternizados, certamente oriunda da nossa longeva tradição de desigualdade, que não poderia deixar de impactar o plano das ideias. O pensamento brasileiro, produzido por uma sociedade com um passado escravista e com um presente de desigualdade no acesso a bens e serviços de toda ordem, inclusive no campo educacional, não poderia deixar de ter, como objetos preferenciais, intelectuais oriundos de nossas camadas dominantes. Contudo, a persistente caminhada de nossas classes populares na direção de maior protagonismo, participação e prestígio se desdobra também no pensamento brasileiro.

Além disso, nosso capitalismo sempre foi pouco propenso à inclusão econômico-social, ficando o mercado em boa medida reservado à burguesia brasileira enquanto espaço social de articulação ou inspiração do pensamento (sendo a burguesia composta por setores ligados à economia privada baseada predominantemente no trabalho assalariado). $\mathrm{O}$ mesmo não pode ser dito em relação ao Estado-Nação, que sempre foi mais capaz de efetivar interfaces com nossas classes populares. No entanto, a longevidade do Estado como locus preferencial de nossas camadas dominantes na operação e reflexão política dedicadas ao planejamento econômico-social do capitalismo nacional revela que quase sempre os piores assentos das institucionalidades e sociabilidades estatais foram ocupados pelos "de baixo". Quanto às universidades brasileiras, desnecessário se estender sobre a ainda modestíssima escolarização em nível superior permitida a nossas classes populares - ainda que haja constante agitação histórica em sentido contrário.

Portanto, os diversos e múltiplos movimentos sociais populares, contestatórios em vários níveis e âmbitos da resiliente desigualdade nacional, foram e continuam sendo lugares sociais próprios para estimular a produção de reflexões mais ou menos críticas ao nosso status quo. Reflexões estas corporificadas em correntes de pensamento como o marxismo, o anarquismo, o 
cristianismo progressista, entre outras vertentes de esquerda. Decerto que tais reflexões não são efetuadas sempre ou necessariamente por intelectuais de origem popular.

De um ponto de vista teórico-metodológico, tentar perceber e dimensionar os lugares sociais de produção e de inspiração das reflexões sócio-políticas a respeito do Brasil implica olhar seletivamente para a relação entre experiências sociais e ideias. Talvez se possa falar numa espécie de alavancagem social das ideias: processos nos quais estratos intelectualizados, impactados por condições sociais e acontecimentos históricos, fornecem nexo e prioridade analítica a certos fenômenos e questões.

Ao tentar operar com a noção de uma alavancagem ou ancoragem social das ideias, intento captar certos tensionamentos sociais e históricos vividos pelos intelectuais na produção do pensamento, de modo a perceber o que Bernardo Ricupero ressalta na análise de Roberto Schwarz sobre certos momentos da obra de Machado de Assis: o fundamento social de impossibilidades e limites - mas também, é claro, de possibilidades e habilitações - de uma obra ou autor (RICUPERO, 2013, p.537).

Sem dúvida há alguma inflexão determinista no esboço de proposição investigativa ora apresentado - de resto, algo recorrente nos modos de ler classistas e marxistas a respeito do pensamento político e social em geral. Por outro lado, "as possibilidades de investigação se empobrecem quando se imagina que se pode recorrer, sem maiores problemas, a qualquer ideia, independente do lugar de onde ela provém", imaginando-se "que elas se encontrariam num ambiente à parte, uma espécie de mundo das ideias” (RICUPERO, 2013, p.542).

\section{Mercado}

O mercado como fomentador de uma certa reflexão política e social a respeito do Brasil tende a produzir diagnósticos como o que segue, do clássico Os donos do poder de Raymundo Faoro, síntese poderosa do modo de pensar a política criado por quem se insere no mundo social tendo o mercado econômico como seu eixo vertebrador maior: "A posição das pessoas politizadas (...), com referência ao governo, assemelha-se (...) aos acionistas de uma sociedade anônima, proprietários da empresa, mas incapazes de a gerir por si mesmos" (Faoro, 1958, p.261). Estado como empresa privada; espírito do capitalismo e ação instrumental espraiados por todo o horizonte social; aposta no indivíduo enquanto cidadão combinada paradoxalmente com uma hierarquização social onde apenas supostas elites são capazes de gerir a sociedade. Estes são alguns dos pressupostos analíticos da leitura liberal no pensamento brasileiro.

A eles se soma a demonização do Estado (protagonista do capitalismo politicamente orientado), concebido em chave pejorativa como a formatação social que historicamente logra 
evitar o bom funcionamento da sociedade à semelhança do mercado. Para tanto, o Estado originalmente nosso "Estado Barroco" - é visto como autonomizado diante da sociedade e de seus grupos e classes sociais componentes (FAORO, 1958, p.9-10, 39-40, 44-45 e 261-263). Neste ínterim, a normatividade liberal do autor parece empoderar sobremaneira o "estamento burocrático", seu seminal conceito. Tal autonomização é de difícil operação analítica em contextos teóricos marxistas, como o próprio Faoro (1958, p.262-263) aponta.

Em contrapartida, sob esse prisma, os agentes estatais são denunciados por lançarem mão de uma diversidade de maneiras de, quase sempre, conspurcar nossa democracia que deveria seguir uma certa normatividade liberal: “As nossas pobres eleições sofrem todos os golpes da influência governamental, os votos são comprados em massa ao eleitor pobre que se beneficia com o exercício de seus direitos cívicos” (FAORO, 1958, p.264-265).

A mesma persistência histórica também pode ser vista no que tange à contradição de nosso "capitalismo político" - outro conceito de Faoro, que completa sua análise dos vícios estatais nacionais - o qual se exime do mercado para funcionar, remetendo ao debate do patrimonialismo na trajetória brasileira (FAORO, 1958, p.267).

A saída deste círculo vicioso é buscada, como é padrão em se tratando do liberalismo, no indivíduo em abstrato, sujeito capaz de empreender a emancipação cidadã (FAORO, 1958, p.264265). De mais a mais, a abstração do indivíduo se afina com o formalismo analítico e propositivo dos liberais brasileiros originais até nossos neoliberais contemporâneos (BRANDÃO, 2005, p.248). A modernidade liberal é tratada como inevitável, sendo qualquer resistência a ela responsável por estagnarmos no atraso histórico em relação ao capitalismo mundial (FAORO, 1958, p.42-43).

\section{Estado-Nação}

A referência - em chave eminentemente positiva - na modernidade capitalista também é um pressuposto no caso do Estado-Nação como lugar social de produção e inspiração do pensamento brasileiro. Seja na versão do autoritarismo esclarecido de Wanderley Guilherme dos Santos ou nas versões nacionalistas originais, seja mesmo quando o marxismo brasileiro se imbricou com o nacional-desenvolvimentismo, a dimensão central comum é a assunção do Brasil aos padrões avançados do capitalismo mundial. Porém, com o Estado-Nação a conduzir nossa modernização, visto que o mercado seria incapaz disso.

Sintetizada de modo notável por Lamounier (1977, p.348 e 357-371), a ideologia de Estado, operando a partir de "consensos valorativos" e do "princípio de autoridade", possuiria as seguintes propriedades: predomínio do princípio estatal sobre o mercadológico, "visão orgânico- 
corporativa da sociedade", “objetivismo tecnocrático", "visão paternalista-autoritária do conflito social", sociedade civil não organizada e não mobilizada, elitismo altruísta e imagem do Estado como um "Leviatã benevolente". O mesmo autor contextualiza a novidade deste pensamento autoritário do início do séc. XX, mostrando que ele estava em consonância com a falência do liberalismo clássico anterior à crise econômica de 1929 e seu "Estado gendarme", que seria substituído pelo "Estado intervencionista" que a ideologia de Estado ajudou a formatar no Brasil.

Além disso, Lamounier (1977, p.372-373) aponta que a receita estatalista em questão pode efetivamente levar a ganhos generalizados, ainda que desigualmente distribuídos entre os diversos grupos sociais. Tal diagnóstico, relativo às proezas sociais realizadas pelo capitalismo brasileiro de orientação estatal, impressiona pela pertinência histórica - tal qual vimos em relação à obra de Faoro (em outra direção). Impossível não arriscar aplicar este modelo, estendido por Brandão (2005, p.246) ao populismo varguista e a outras experiências políticas brasileiras, ao que hoje se chama lulismo, que traria alguns elementos comuns àquela ideologia de Estado.

Lamounier registra também as importações culturais realizadas pioneiramente pelos primeiros representantes da ideologia de Estado, uma vez que trouxeram da Europa múltiplas formulações ideológicas antiliberais: positivismo, organicismo, romantismos, historicismos e elitismos, entre outras, que ajudaram a alimentar corporativismos, fascismos e outras tendências político-sociais alternativas ao liberalismo (LAMOUNIER, 1977, p.345-346 e 361-362).

Sem dúvida fez parte dessa leva ideológica uma corrente oriunda do positivismo e relacionada ao corporativismo: o funcionalismo durkheimiano. Este pressupunha um papel destacado à ciência e ao Estado na modernização da Nação francesa. Depois, ele foi tomado como modelo para outras nações, europeias ou não. Daí o supramencionado "objetivismo tecnocrático" registrado por Lamounier. O Estado-Nação, por meio de elites políticas e/ou burocráticas, acionando a ciência, teria condições de levar à frente a necessária modernização a que toda sociedade almeja, de modo planejado - não do modo aleatório e incerto propugnado pelos defensores do mercado, os liberais. Certamente que a ciência subsidiaria tais elites por meio da ação de intelectuais junto ao Estado, os quais poderiam ser inclusive confundidos com elas.

Para tanto, esses intelectuais se comportariam e se configurariam como uma intelligentsia, numa certa acepção mannheimiana (MANNHEIM, 2001), uma vez que estariam um tanto desconectados dos demais grupos e classes sociais. Sendo capazes, portanto, de não confundir os interesses desses setores sociais ordinários com os interesses maiores da Nação, definidos cientificamente. Aqui configura-se a típica perspectiva objetivista, instrumental, do positivismo. Esta intelligentsia, assim talvez como as elites políticas/burocráticas as quais estariam associadas ou das quais faria parte, localizando-se - ou imaginando localizar-se - na posição superior do Estado-Nação, parece supor-se livre não apenas de tentações ideológicas mas, no limite, de 
determinações sociais, notadamente as de classe.

Mas esse viés cientificista, moderno, do nosso pensamento político e social contíguo ao Estado-Nação não necessariamente é a única vertente reflexiva existente junto a esse lugar de produção e inspiração do pensamento brasileiro. Primeiramente porque, conforme já visto com Brandão, seus antepassados são anteriores à "chegada" da modernidade no Brasil - Visconde de Uruguai viveu num país escravista. Em segundo lugar, porque uma outra corrente de ideias, bastante diversa do funcionalismo e do positivismo, acabou por protagonizar, talvez não apenas no Brasil, um feliz encontro com a esfera da dominação política e burocrática reservada ao Estado: o romantismo.

Lamounier (1977, p.362) avalia que no caso brasileiro o viés conservador de tendências como o romantismo prevaleceu. Não obstante, o pensamento brasileiro convergente com o EstadoNação - a ideologia de Estado - se mostrou bem mais reformador que nosso liberalismo quase sempre oligárquico. De qualquer maneira, o romantismo no pensamento brasileiro também empoderou o Estado-Nação como polo de resistência às promessas e ilusões liberais. Portanto, o atraso brasileiro no diagnóstico liberal é invertido, tornando-se nossa vantagem que propicia um caminho próprio à modernidade, como afirma Luiz Werneck Vianna a propósito da leitura de Richard Morse sobre a América Latina (VIANNA, 1991, p.147).

Nesse sentido, romantismo tradicionalista e certo cientificismo positivista poderiam superar a distância de seus pressupostos teóricos em favor da convergência na oposição ao liberalismo ortodoxo, aquilatado como inaplicável à realidade brasileira. Mais do que isso: podem ser emparelhadas a imagem tradicionalista de qualquer sociedade - organizada hierarquicamente como um edifício onde os estamentos sociais se relacionam desigualmente sob comando de uma autoridade tradicional - e a imagem funcionalista de qualquer sociedade - onde seus grupos sociais articulados funcionalmente exercem suas atribuições numa configuração não-igualitária sob o comando de uma autoridade cientificamente legitimada.

Procedendo de maneira oposta ao pensamento fincado na experiência e na noção de mercado, cientificismos e romantismos (que talvez possam ser sociologicamente agrupados como funcionalismos nos planos teórico e analítico) conectados a um Estado-Nação - real ou imaginário - promovem a demonização do mercado como responsável por todos os problemas brasileiros. Mas a operação do pensamento aqui vai mais além: as sociedades nacionais são concebidas com claro privilegiamento epistemológico. Isto é, ainda que possam ser compostas por grupos sociais diversos, a unidade da Nação é maior que a soma de suas partes e os conflitos internos à sociedade nacional são considerados intelectual e politicamente menos relevantes que as oposições entre Nações e seus Estados. Há, portanto, uma suposição, mesmo que difusa, de alguma harmonia, existente ou a ser perseguida, na sociedade nacional. Como já mostrava Francisco Weffort, a 
noção de "povo", o qual seria o substrato de qualquer sociedade nacional moderna, omite as contradições de classe, além de supor que povo se constitua enquanto comunidade (WEFFORT, 1980, p.37-38).

Evidência clara a respeito pode ser encontrada na reflexão de Nelson Werneck Sodré, intelectual marxista do Pcb tão próximo do isebianismo. Nela a prioridade analítica na interpretação do Brasil em todas as etapas de sua história é fornecida ao conceito de "povo" em detrimento das categorias classistas do marxismo: com o povo - onde se amalgamam trabalhadores, camponeses, pequena-burguesia e burguesia nacional - como fruto de uma aliança poli-classista arquitetada e liderada por uma vanguarda (intelligentsia?), era possível fortalecer as ações do Estado-Nação em prol do desenvolvimento nacional (SODRÉ, 1967, p.207-208). Ou seja, do ponto de vista metodológico pertinente ao estudo do pensamento brasileiro, verifica-se que o diapasão estatal-nacional se sobrepõe ao critério de classe. Operação do pensamento similar pode ser encontrada em outro marxista pecebista importante da história e do pensamento brasileiro, Alberto Passos Guimarães. Ao defender a tese das origens feudais de nossa formação socioeconômica (o que é condizente com a visão oficial da III Internacional Comunista), ele afirmava que Portugal transferira para o Brasil colonial os aspectos mais regressivos do modo de produção ainda vigente na metrópole - no caso, o feudalismo (GUIMARÃES, 1977, p.22). As relações sociais de produção, tão determinantes na perspectiva marxista, nesta operação teórica e analítica tornam-se mero objeto de decisão das camadas dirigentes de um Estado-Nação. Fica evidente o privilegiamento epistemológico do primado estatal-nacional em detrimento do paradigma classista.

\section{Campo acadêmico}

Leituras do Brasil que invertam a relação dada acima entre a perspectiva referida ao Estado-Nação e a perspectiva classista podem ser encontradas em vários autores, inclusive em alguns cujas reflexões teriam sido ancoradas tanto pelo espaço acadêmico como pelo campo dos movimentos sociais das classes populares. A respeito, sem dúvida um autor exemplar é Florestan Fernandes. Em sua análise constante de A Revolução Burguesa no Brasil, afirma: "é a impotência da burguesia brasileira - fruto de sua relação com o imperialismo - que faz com que sua ação convirja para o Estado - assim seria em torno do Estado que as classes dominantes se unificam" (RICUPERO, 2015, p.55). Temos então o Estado-Nação como elemento em boa medida determinado ontologicamente pelas relações de classe - estas agora constitutivas do polo analítico dominante.

Não por acaso tratamos de Florestan Fernandes neste momento. Ele é considerado o maior 
responsável pela substituição dos ensaios como forma clássica de interpretação do Brasil, elaborados por muitos de nossos intelectuais perfilados com o Estado-Nação, pelo estilo monográfico vinculado à emergência social e institucional das universidades como lugar por excelência da atuação intelectual em nosso país (RICUPERO, 2015, p.48). Embora sua obra acima mencionada seja exatamente um ensaio, do período da ditadura militar iniciada em 1964.

As universidades e outras modalidades institucionais correlatas, que comporiam um campo acadêmico que se concebe a partir de Bourdieu, constituem outro lugar social, estratégico, de fomento e balizamento do pensamento político e social brasileiro.

A significativa autonomia conquistada pelos intelectuais universitários na história mundial pode ser lida, de um modo um tanto enganoso: de modo a identificá-los diretamente com a intelligentsia conceituada por Mannheim. No entanto, na leitura que ora realizo, tal categoria mannheimiana remete em demasia os intelectuais para fora das relações e conexões sociais a que todo agrupamento de indivíduos não pode escapar totalmente. Em contrapartida, para não oscilar fortemente em sentido contrário, tomando desde já para este pequeno trabalho o conceitual gramsciano, que enfatiza justamente os liames que prendem os intelectuais aos grupos sociais, o meio-termo disponível é a teorização dos campos intelectuais em Bourdieu. Nela, a autonomia dos campos intelectuais, particularmente do campo acadêmico, efetiva-se enquanto mediação entre os intelectuais universitários e os demais espaços sociais. Em outras palavras: o intelectual acadêmico serve à sociedade e é por ela condicionado na medida do exercício do livre-pensar e do respeito ao princípio weberiano de neutralidade científica que caracteriza seu habitus, os quais dão a impressão do contrário - de que ele não atende à sociedade nem por ela é impelido (BOURDIEU, 1989, p.101-102).

Ademais, as universidades constituem um espaço de profissionalização próprio, que preenche de nexo existencial singular boa parte da vida de professores e pesquisadores. O campo acadêmico costuma possuir regras internas meritocráticas, de viés procedimentalista orientado para a pesquisa científica, objetivando resultados da produção intelectual em feição monográfica, num contexto de um pluralismo teórico aparentemente ilimitado. Por conseguinte, o intelectual acadêmico deve seu prestígio social quase que exclusivamente ao tipo de capital cultural peculiar que detém, em boa proporção independente das influências diretas do capital econômico.

Importante registrar que o triunfo social da intelectualidade acadêmica sobre a intelligentsia referenciada no Estado-Nação é demarcada, no campo de estudos do pensamento político e social brasileiro, pela conversão institucional - mas não político-ideológica - de pensadores como Wanderley Guilherme dos Santos, que após o fechamento do Iseb pela ditadura militar foi atuar no Iuperj, hoje Iesp/Uerj, típica instituição de pós-graduação universitária. Em sentido contrário, renovam-se os exemplos de institucionalidades estatais que ofertam espaços 
para intelectuais acadêmicos atuarem como - ou se converterem em - membros da intelligentsia estatal-nacional: Ipea, Bndes, entre outros.

Face à pluralidade teórica e ideológica presente no campo acadêmico, é possível indagar se faz sentido imaginar as universidades como lugar social de impulsionamento do pensamento brasileiro, dada a aparente ausência de orientação reflexiva hegemônica. Em resposta, pode-se afirmar que o formato monográfico em si não é neutro, já trazendo consigo certos significados, segundo as circunstâncias históricas vigentes em cada situação - de resto, conhecidas no caso brasileiro por ocasião do embate com o estilo ensaístico. Pode-se afirmar também que aquele pluralismo é matizado pela inserção específica dos intelectuais universitários nas sociabilidades de que participa, por conta do forte mas ainda assim variável prestígio social que as universidades carreiam para seus membros. Mas, além disso, a autonomia vivenciada em maior ou menor grau por professores/pesquisadores sem dúvida tensiona de determinadas maneiras o pensamento a respeito do Brasil por eles produzido. E é possível supor que o campo acadêmico, enquanto alavancador social de um certo pensamento político e social, tem a peculiaridade de imbricar seu impulso reflexivo próprio com outros impulsos, como os oriundos do mercado, do Estado-Nação e dos movimentos populares.

Para ilustrar tal combinação de alavancagens sociais no pensamento brasileiro recorro novamente a Florestan Fernandes, que se define duplamente ao definir seu A Revolução Burguesa no Brasil como um ensaio de um sociólogo que também é um militante socialista (RICUPERO, 2015, p.48-49). Considerando a interação com os movimentos sociais das classes populares como o diapasão inescapável da esquerda, é notável como a percepção dessas classes e grupos correlatos no pensamento brasileiro foi rarefeita em boa parte de nossa reflexão política e social, marcada tão positivamente pela intelectualidade de esquerda.

\section{Movimentos sociais das classes populares}

Creio que um olhar político-social voltado privilegiadamente para nossas classes populares, enquanto atores coletivos fundamentais na trajetória brasileira, amadurece em nosso pensamento apenas a partir dos anos 1960. Tal olhar passa a ser definidor de um novo período do pensamento político e social brasileiro a partir das duas décadas seguintes. Impactados pelo novo sindicalismo e pelos novos movimentos sociais nacionais florescentes nos anos 1970/80, críticos do populismo e do pecebismo e profissionalizados no campo acadêmico em proporção inédita em nossa história, muitos intelectuais brasileiros construíram um viés analítico menos elitista para nosso pensamento, por meio de uma "inflexão fenomenológica" que fornecia centralidade teórica às diversificadas ações coletivas das classes populares nacionais na explicação do que é o Brasil 
(PERRUSO, 2009).

O elitismo presente no pensamento político e social brasileiro desde suas origens é facilmente notado em nosso liberalismo, conforme já visto a propósito da obra de Faoro. Sua visão hierarquizada do mundo social brasileiro, apesar dos pressupostos individualista e igualitário adotados, é encontrada em várias passagens de Os donos do poder. Citando a sociologia de Michels, ele assevera que "os cidadãos, mesmo em uma democracia altamente envolvida, não poderiam governar diretamente". Tal crítica da democracia participativa em favor da democracia representativa é acompanhada de uma relativização do mérito original desta última: "A minoria dirigente - a elite - nunca é verdadeiramente fiel à maioria que ela representa" (FAORO, 1958, p.261). Trocando o plano normativo pelo da observação empírica da sociedade brasileira, o diagnóstico é similar. Veja-se seu julgamento das capacidades cidadãs de nossas classes populares: "o povo inculto e de costumes primários, ausente do interesse pela coisa pública, mesmo na pequena parcela que vota, não tem sombra de conhecimento da máquina governamental e administrativa" (FAORO, 1958, p.264). Dada esta apreciação pessimista das possibilidades de compreensão do funcionamento do Estado moderno pelo cidadão comum, pode-se presumir como é dominante o viés cientificista, tecnocrático mesmo (que em tese deveria ser apenas da ordem do Estado-Nação), no pensamento brasileiro referido no mercado.

Do lado do pensamento brasileiro vinculado ao Estado-Nação, o quadro parece ser o mesmo, ainda que com outras matizações. Para não falar dos pensadores autoritários da República Velha e suas assertivas antipopulares (quando não racistas), recorro, para efeito de ilustração, a Nelson Werneck Sodré, cujo antiliberalismo é nitidamente aproximado à esquerda. Em sua Introdução à Revolução Brasileira, as classes populares nacionais - compostas por uma minoria de trabalhadores livres e uma maioria de servos e escravos (visto ser ele adepto da tese das origens feudais de nossa sociedade) - são quase sempre julgadas negativamente quanto ao desenvolvimento de uma consciência política. Se no período colonial até a Proclamação da República tais grupos sociais possuem nenhuma ou pouca consciência, à medida que paulatinamente passam a tê-la, seguem enquanto "massa" dependentes da direção de uma vanguarda esclarecida, não por acaso composta por uma pequena-burguesia - de que certamente os intelectuais fazem parte como intelligentzia (novamente o cientificismo e um tecnocratismo se fazem presentes). Além disso, considera ele que nosso campesinato move a vida econômica nacional, ficando a vida intelectual circunscrita fundamentalmente à pequena-burguesia (SODRÉ, 1967, p.199-200 e 234-235). O fato de fornecer centralidade socioeconômica ao campesinato, coerente com uma leitura marxista possível a respeito da história brasileira, é contrabalançada pela desconsideração da vida cultural desta mesma classe social. Aqui estão conjugados dois planos: o da presença das classes populares no pensamento brasileiro e o da presença do pensamento 
impulsionado por tais classes em nossa reflexão política e social.

Já Caio Prado Jr. é um dos pioneiros na produção intelectual brasileira que reserva para nossas classes populares um lugar não apenas central, mas necessariamente decisivo nos processos por que passa nossa sociedade. Após o golpe militar de 1964, em A Revolução Brasileira, ele indicava que exclusivamente nossa classe trabalhadora rural seria capaz de eliminar nossos resquícios coloniais, em aliança com o operariado urbano. Ademais, propugnava de modo mais amplo a organização autônoma de nosso proletariado, por meio do movimento sindical, como prérequisito para a modernização societária nacional (PRADO JR., 1987, p.171-176). Assim, ia de encontro às construções populistas e pecebistas em torno do "povo", as quais receitavam a imersão dos trabalhadores no seio de uma aliança poli-classista com a burguesia nacional e os intelectuais pequeno-burgueses como fórmula capaz de nos modernizar, por meio do desenvolvimento nacional comandado pelo Estado.

$\mathrm{Na}$ mesma direção, pode-se trazer as reflexões de Francisco Weffort a respeito do populismo e do movimento operário no Brasil. Ao argumentar que os setores dirigentes da sociedade brasileira sempre buscaram compromissos conciliatórios que evitassem algum protagonismo social e político das massas populares (WEFFORT, 1980, p.15), ele parece subverter a virtuosidade da relação vanguarda-massa em Sodré. Mais importante: ao formular que o desenvolvimento capitalista industrial no Brasil colocou um desafio comum a outras sociedades, qual seja, como incorporar as massas à democracia burguesa (WEFFORT, 1980, p.17), ele situa com absoluta centralidade as classes populares numa interpretação - e interpelação - do Brasil. De fato, a partir dele e de outros autores, como Caio Prado Jr., o pensamento político e social nacional observa e pondera de outra forma as potencialidades dos trabalhadores e de seus movimentos na configuração social, política e cultural do Brasil.

Neste ínterim se insere um momento crucial nas reflexões de Weffort. Ele chama atenção para a superioridade de nosso sistema populista inaugurado em 1930 (para cuja criação nossos intelectuais referenciados no Estado-Nação concorreram) sobre o regime liberal-oligárquico anterior (obra comumente atribuída ao pensamento brasileiro polarizado pelo mercado), uma vez que naquele os interesses das massas populares passaram a ser levados em conta na cena política (WEFFORT, 1980, p.21-22). Mas esse mérito, em outra passagem, é creditado às lutas sociais protagonizadas pelos trabalhadores e demais setores populares no pré-30 (WEFFORT, 1980, p.67). Assim, ao remar contra a corrente da visibilização que nosso pensamento político e social confere às camadas dirigentes/dominantes nacionais (no caso, representantes políticos ou intelectuais do populismo), Weffort indica que se fazia necessário, metodologicamente, mudar a mirada sobre os grupos sociais que compunham a sociedade brasileira, proporcionando centralidade ontológica aos "de baixo" na interpretação do país. 
Tal inversão de perspectiva analítica tem forte teor classista. A partir dela e de similares mudanças teóricas e analíticas efetuadas por outros autores, pôde-se buscar mais vastamente nos movimentos sociais das classes populares as evidências de que os destinos do Brasil sofreram e sofrem a interferência de quem parecia nunca estar presente efetivamente em nossa cena política. A profusão de investigações sobre os movimentos sindicais e sociais nos anos 1970/80 pendeu, inclusive, para uma visão romântica de nossas classes populares. Romantismo este que se traduzia numa desconfiança em relação às promessas de modernização, fossem elas operadas na lógica do mercado ou do Estado-Nação. Em outras palavras, se aclarava uma perspectiva crítica em relação à velha ideia de progresso (na versão brasileira, desenvolvimento nacional), progresso sempre acompanhado de contradições para os trabalhadores.

\section{Considerações finais}

A partir desse ponto também é possível demarcar que mercado e Estado-Nação, com suas típicas e distintas razões da modernidade, constituíram, na trajetória brasileira, lugares quase exclusivos para a formulação de um pensamento político e social tensionado por experiências diversas de dominação exercida sobre as classes trabalhadoras. Alternativamente, os mundos da vida (no sentido habermasiano) das classes populares, e de suas movimentações societárias em sentido contestatório, ensejaram outro campo de tensões, que foi subsidiando reflexões políticas e sociais variadas, seja de intelectuais orgânicos das camadas populares, seja impactando intelectuais acadêmicos. O que não quer dizer que a universidade como lugar social de produção do pensamento não receba também influxos oriundos do Estado-Nação e do mercado - sobram evidências neste sentido.

De qualquer maneira, ofertava-se uma inteligibilidade diferente para interpretar a sociedade brasileira, a qual normalmente vem acompanhada do engajamento de intelectuais em movimentos sociais - e partidos políticos - ligados às classes populares e à esquerda. Contudo, não se deve confundi-lo com o engajamento no Estado-Nação ou com a confiança universal no mercado, nem com a pretendida neutralidade científica subjacente ao campo acadêmico.

Desta maneira, a observação e a valorização científica da diversidade de vivências e experiências de nossos setores subalternos entrava na ordem do dia de uma compreensão mais densa sobre a sociedade brasileira. 


\section{Referências}

BOURDIEU, Pierre. O poder simbólico. 1a. edição. Lisboa/Rio de Janeiro: Difel/Bertrand Brasil, 1989.

BRANDÃO, Gildo Marçal. Linhagens do pensamento político brasileiro. Dados - Revista de Ciências Sociais, Rio de Janeiro, 2005, v. 48, n. 2, pp. 231-269.

FAORO, Raymundo. Os donos do poder - formação do patronato político brasileiro. 1a. ed. Rio de Janeiro: Globo, 1958.

FERNANDES, Florestan. A revolução burguesa no Brasil - ensaio de interpretação sociológica. $2 \mathrm{a}$. Ed. Rio de Janeiro: Zahar, 1976.

GUIMARÃES, Alberto Passos. Quatro séculos de latifúndio. 4a. edição. R. de Janeiro: Paz e Terra, 1977.

GRAMSCI, Antonio. Os intelectuais e a organização da cultura. 5a. edição. Rio de Janeiro: Civilização Brasileira, 1985.

HABERMAS, Jürgen. Teoría de la acción comunicativa - crítica de la razón funcionalista. Tomo II. Madrid: Taurus, 1987.

LAMOUNIER, Bolívar. Formação de um pensamento político autoritário na Primeira República: uma interpretação. In: FAUSTO, Boris. (org.) História geral da civilização brasileira - o Brasil republicano. 1a. edição. São Paulo: Difel, 1977.

LEAL, Victor Nunes. Coronelismo, enxada e voto - o município e o regime representativo no Brasil. 4a. edição. São Paulo: Alfa-Ômega, 1978.

MANNHEIM, Karl. Sociologia da Cultura. 2a. edição. São Paulo: Perspectiva, 2001.

PERRUSO, Marco Antonio. Em busca do "novo" - intelectuais brasileiros e movimentos populares nos anos 1970/80. 1a. edição. São Paulo: Annablume, 2009.

PRADO JR., Caio. A Revolução Brasileira. 7a. edição. São Paulo: Brasiliense, 1987.

RICUPERO, Bernardo. Florestan Fernandes e as interpretações do Brasil. In: CEPÊDA, Vera Alves \& MAZUCATO, Thiago (org.) Florestan Fernandes 20 anos depois - um exercício de memória. 1a. edição. São Carlos: Ed. Ufscar, 2015.

RICUPERO, Bernardo. O lugar das ideias: Roberto Schwarz e seus críticos. Sociologia \& Antropologia, Rio de Janeiro, 2013, v. 3, n. 6, pp. 525-556.

SADEK, Maria Tereza. Análises sobre pensamento social e político brasileiro. BIB - Boletim Informativo e Bibliográfico de Ciências Sociais, Rio de Janeiro, 1982, n. 12, pp. 7-21.

SCHWARZ, Roberto. Cultura e política. 1a. edição. São Paulo: Paz e Terra, 2001.

SODRÉ, Nelson Werneck. Introdução à Revolução Brasileira. 3a. edição. Rio de Janeiro: Civilização Brasileira, 1967.

VIANNA, Luiz Werneck. Americanistas e iberistas: a polêmica de Oliveira Vianna com Tavares Bastos. Dados - Revista de Ciências Sociais, Rio de Janeiro, 1991, v. 34, n. 2, pp. 145-189.

WEFFORT, F. O populismo na política brasileira. 2a. edição. Rio de Janeiro: Paz e Terra, 1980. 